\title{
Spurring the Uptake of Maternal Healthcare Services in Culturally Endowed Communities in Elgeyo Marakwet, Kenya
}

\author{
Cheboi Solomon Kemoi ${ }^{1,3^{*}}$, Kimeu Anastasiah Nyamilu Mailu², Rucha Kenneth \\ Kibaara $^{3}$
}

OPEN ACCESS

Citation: Cheboi Solomon Kemoi, Kimeu Anastasiah Nyamilu Mailu, Rucha Kenneth Kibaara. Spurring the Uptake of Maternal Healthcare Services in Culturally Endowed Communities in Elgeyo Marakwet, Kenya. Ethiop J Health Sci. 2020;30(2):160. doi:http: //dx.doi.org/10.4314/ejhs.v30 i2.2

Received: August 29, 2019

Accepted: October 10, 2019

Published: March 1, 2020

Copyright: (2020 Cheboi K.S., et al. This is an open access article distributed under the terms of the Creative Commons Attribution License, which permits unrestricted use, distribution, and reproduction in any medium, provided the original author and source are credited. Funding: Nil

Competing Interests: The writers declare that all authors in its form approved this manuscript and that no competing interest exists.

Affiliation and Correspondence:

${ }^{1}$ Centre for Biodiversity, National

Museums of Kenya, Nairobi

${ }^{2}$ Institute of Capacity Development,-

Amref Health Africa, P.O. Box 27691, 00506 Nairobi, Kenya

${ }^{3}$ Department of Health Management and Health Informatics, Kenyatta

University. P.O. Box 43844 - 00100

Nairobi, Kenya

*Email: solocheboi@gmail.com

\section{ABSTRACT}

BACKGROUND: Enhancing the well-being of the mother and newborn is an explicit goal in health. Of the most legendary neglected influencer is patient centered requirement. The hope for people-oriented maternal health interventions in societies is hinged on cultural differentials therefore, contextualizing beliefs, values and expectations is important. A study to identify maternal healthcare services needs amongst women in Marakwet communities was undertaken.

MATERIALS AND METHODS: This was an explorative qualitative study. A stratified list of cultural subgroups was developed and used to purposively select study participants. Twelve focus group discussions (FGDs) and fourteen key informant interviews (KIIs) were undertaken. Data was collected using semi-structured FGD and KII guides. The data was analyzed using five steps of conventional content analysis.

RESULTS: The finding of the study revealed that support and care during pregnancy, labour, childbirth and postpartum are systematic defined informational, instrumental and emotional processes pivoted by individual and society pathways. Social-cultural needs include continuous pregnancy and labor care, companionship, elective delivery methods, placenta interpretation, placenta disposal, newborn celebration, privacy and mother-child welfare services. Choice of delivery assistant is a dynamic social construct informed by cultural values such as initiation, age, gender and experience. Health behavior dynamics is therefore context-dependent, embodied by social network and social support as well as psychological and physiological expectation.

CONCLUSION: Women maternity needs are multiple and diverse. Adapting care to meet the contextualized individual and community needs may spur positive maternal health seeking behaviour among women and assist healthcare workers to provide culturally competent care to improve health outcomes. Educational outreach and behaviour change communications to demystify and tackle retrogressive cultural practices should be increased.

KEYWORDS: Needs, pregnancy, maternal health, care seeking behaviour, Marakwet 


\section{INTRODUCTION}

There has been impressive progress in reducing maternal mortality and morbidity worldwide with substantial achievement in sub-Saharan Africa. However, considerable inequalities are prevalent amongst socially endowed and non-endowed women (1,2). Maternal mortality amongst marginalized women in Mexico was five times higher than that of non-marginalized women (3). In Australia, maternal death rate for marginalized women was three times higher compared to nonmarginalized women between 2006-2010 (4). African data has not been disaggregated into special marginalized groups such as Berber, Haratin and Sahawi of North Africa, Batwa of Central Africa, Sengwer and IL Chamus of East Africa (5). This makes comparative studies from Africa hard to find. In Kenya, though skilled deliveries is $44 \%$ amongst vulnerable and marginalized women compared to $68 \%$ nationally (2). Fraction of expectant women who meet the standard antenatal or postnatal service is on the decline whilst the uptake of family planning services is spotty (2).

The social determinants of health are mostly responsible for health inequities (6). However, it is now evident that tweaking the one-size-fits-all approach to a more socially supportive environment is the optimum way of reducing health inequities $(6,7,8,9)$. Elmusharaf and company arguments that universal maternal health access will be optimally achieved when women are cared and empowered to make their own health care decision in a supportive environment (8). Wilson et al., shares this emphasis and writes that there is no "one-size-fits-all" solution. Nevertheless, understanding personal, and community needs may provide a framework for hospitals to develop and employ practices to meet diverse patient needs (9). Tariq and Durrani aver that optimum and successfully delivery by health workforce lies in its ability to being sensitive to the culture and context of their communities (7). Ishepe and colleagues opine that heightened mortality and morbidity in these groups may only be reduced when cultural barriers and providerrecipient relationship are neutralized (2).
Insufficient data and limited published literature limit contextually based interventions to improve these statistics on marginalized women (8). Planning and accountability for improving maternal health calls for initiatives and research on needs and preference as an anchor to culturally appropriate services (10). Variances amongst the cultural needs, values and preferences of women during pregnancy, labor and delivery are unique and diverse (10). Whereas every woman seeking maternal health services has expectations, desires and aspirations (11), it is important to understand that not all those within a group will adhere closely to a logarithm (12). Cognizant of these, classifying women's expectations may trigger human resource for health (13) to provide equitable maternal services across ethnic groups (14). Hence, a qualitative study was undertaken to identify maternal healthcare interventions requirements to inform action for fragile women in Elgeyo-Marakwet County, Kenya.

\section{MATERIALS AND METHODS}

Design: This descriptive explorative qualitative study focused on indigenous cultural needs, which inform maternity health seeking behaviour amongst the Marakwet community. The finding informed a cluster randomized controlled trial (CRT) investigating the effect of training health workers in cultural competence care.

Study site: The study was conducted in Marakwet East Sub County, Kenya. The topography of Marakwet East includes the northern part of the Kerio Valley, Elgeyo Escarpment and Highlands. Marakwet is the main ethnic group split into Sambirir, Kapyego, Endo, and Embobut/Embolot (Sengwer) with unique but interrelated cultural values. According to Kipchumba, various cultural themes are important in various pedigrees across various subtribes and clans among the Marakwet (15). The cultural themes include marriage, pregnancy, delivery, weddings, initiation, abortion, murder, death, oath, suicide, aging, diseases, and hunger.

Study population: The study discussants were women of reproductive age who had not taken part in quantitative client exit survey. Key informants were cultural anthropologist, culturist

DOI: http://dx.doi.org/10.4314/ejhs.v30i2.2 
traditionalist, gatekeepers, and healthcare providers.

Sampling technique: A catchment facility-based qualitative interview was done. Focus group discussion and Key Informant Interviews (KII) were undertaken in each facility catchment area. For group homogeneity, participants in FGD were selected purposively with cascaded age, number of children, and experience, and sub tribe, level of education, income level and cultural diversity. The purposive sampling helped to select cultural grounded people, experienced and exposed on maternity services as well as set environment for peers to talk and express freely.

Data collection tools: Data was collected using semi-structured FGD and KII guides in the months of July-September 2018. The major themes in the tools included indigenous maternal care practices relative to conventional maternity services, socialcultural maternity needs, knowledge and beliefs, patients' behavioural patterns, and expectations in context to community maternal healthcare amenities and opportunities.

Validity and reliability: Content and concurrent validity were tested. Cultural experts for consistency with study objectives and themes crosschecked the research materials. The study adopted equivalence approach to assess tool reliability, which according to Polit and Hungler, (1999), as cited by Nandjila is where two, or more observers (raters) use an instrument to measure the same phenomena and comparing the results (16). In this study, two independent persons who were not part of the study but experts in the area of cultural competence reviewed the tools. The experts and the authors reviewed feedback and assessed whether the experts interpreted the questions on the same scope and values in a panel discussion. Formative FGD was undertaken with a culturist to ensure the right terminology and questions were used. Daily debriefs were held with the research team to highlight key issues and to validate the emerging key outcomes. An immersion session was undertaken with women of reproductive age and culturist from five territorial sections of Marakwet; namely Almoo, Sengwer, Endoow, Sombirir, and Mokoro. Others included health providers, administrators and the research team. The use of immersion was to validate and gather in-depth insights on topics, inculcate ownership and embed the research findings among locals, providers and administrators.

Data collection procedure: FGD sessions were conducted in private venues for confidentiality and sound ambience. One FGD had 8-12 people. Prior to the FGD session, the participants were screened appropriately; ground rules were set, study objectives shared and discussant tagged for confidentiality. For optimum interaction, a semicircle-sitting arrangement was set and participants requested to speak one at time. The session started with general questions to specifics. The participants were given opportunity to cocreate and simulate situations, where phenomenon and needs were applicable. Co-creation approach provided a structured role-play to gather insights on how best discussants felt about current maternity services, important social cultural maternity needs and suggestive ways of integration for optimum benefits as well as uptake. The average FGD duration was 76 minutes. Rapid analysis informed incorporation of emerging issues in the subsequent groups. The study team took moderation and data notes interchangeably.

The study was approved by Kenyatta University Ethical and Research Committee. KU/ERC/APPROVAL/VOL.1 (164) and National Commission of Science, Technology and Innovation NACOSTI/P/18/41197/21776 and Elgeyo Marakwet County government EMC/CDMS/GC/2018 (39). The three core principles of human subject; namely, respect for persons, beneficence, and justice were followed. The purpose, risks, benefits and use of results, were explained. Study participation was voluntary. Data analysis: Inductive and deductive approaches were applied. Inductive analysis using open coding and progressive categorization was used to examine emerging issues for modification and emphasis of subthemes in subsequent sessions. Deductive analysis tracked the trend of key issues developed and framed at the design stage. Categories derived from the data were analyzed through the development of analysis charts, guided by social ecological model of needs. 
The five steps of qualitative analysis as guided by Graneheim and Lundman were applied. Repeated text formed units and units shaped subcategories (17). The subcategories were condensed to subthemes and subsequently to key themes.

\section{RESULTS}

The findings are derived from 12 FGDs and 14 KIIs. Verbatim and narrations are provided to

Table 1: Maternal health care needs and opportunities. corroborate gray meaning and value of needs. The research findings revealed continuous pregnancy and labor support and care, companionship, elective delivery methods, placenta interpretation, placenta disposal, newborn celebration, privacy and mother-child welfare services as key traditional maternal health care needs as presented in Table 1.

\begin{tabular}{|c|c|c|}
\hline Subtheme & Expectation & Recommendation \\
\hline $\begin{array}{l}\text { Continuous support } \\
\text { and companionship }\end{array}$ & $\begin{array}{l}\text { - Provides reassurance and } \\
\text { comfort }\end{array}$ & $\begin{array}{l}\text { - Enhance moral and psychological support in } \\
\text { delivery rooms through integration of } \\
\text { continuous support into maternity care services. }\end{array}$ \\
\hline Delivery position & $\begin{array}{l}\text { - Varied delivery options for } \\
\text { women }\end{array}$ & $\begin{array}{l}\text { - Educate women on pros and cons of childbirth } \\
\text { delivery methods in ANC talks and granting } \\
\text { opportunity for preferred method when } \\
\text { appropriate. }\end{array}$ \\
\hline $\begin{array}{l}\text { Placenta } \\
\text { interpretation and } \\
\text { disposal }\end{array}$ & $\begin{array}{l}\text { - Reverence of the placenta, its } \\
\text { interpretation and disposal. }\end{array}$ & $\begin{array}{l}\text { - Allow companions to observe, interpret and } \\
\text { dispose the placenta in aseptic ambience. } \\
\text { - Promote disposal of placenta in cultural friendly } \\
\text { sites and approach. } \\
\text { - Health education to demystify placenta myths } \\
\text { and beliefs }\end{array}$ \\
\hline $\begin{array}{lr}\text { Feedback } & \text { and } \\
\text { Celebration } & \text { of } \\
\text { newborns } & \\
\end{array}$ & $\begin{array}{l}\text { - Recognition of the social and } \\
\text { personal values and tenets of } \\
\text { welcoming newborns }\end{array}$ & $\begin{array}{l}\text { - Allow community to fete the coming of } \\
\text { newborns in the context of the community }\end{array}$ \\
\hline Delivery Assistant & $\begin{array}{l}\text { - Social constructs: initiation, age, } \\
\text { gender and experience inform } \\
\text { preference of assistant }\end{array}$ & $\begin{array}{l}\text { Promote acceptance of male, uncircumcised } \\
\text { and young delivery assistant. }\end{array}$ \\
\hline Mother-child welfare & $\begin{array}{l}\text { - Massage, supply of merchandise } \\
\text { (basins, slippers, baby clothes } \\
\text { and sanitary) are important }\end{array}$ & $\begin{array}{l}\text { - Advocate the scaling up of the maternity pack } \\
\text { practice } \\
\text { - Allow companions to provide cultured massage } \\
\text { therapy and support }\end{array}$ \\
\hline $\begin{array}{l}\text { Privacy and } \\
\text { confidentiality }\end{array}$ & $\begin{array}{l}\text { Respect of women rights to } \\
\text { private and conducive maternity } \\
\text { services. } \\
\text { - Use of gloves appropriately in } \\
\text { respect to clients condition }\end{array}$ & $\begin{array}{l}\text { - Promote enhancement of privacy and } \\
\text { confidentiality during labour and delivery } \\
\text { - Promotion the use of PPE rightfully } \\
\text { - Advance inclusion of de-stigmatization talks in } \\
\text { ANC fora }\end{array}$ \\
\hline
\end{tabular}

Support and companionship during pregnancy and delivery: The study revealed that support, care during pregnancy, labour, childbirth, and postpartum are systematic defined processes. One contributor elaborated, 'continuous support transcending from pregnancy, labour to delivery is very important in a woman's life'. Support and care is twofold: personalized and community support but with similar goal. Personalized support is a mother mentor (Kogopo kaw)-pregnant woman relationship. While community support entails peers, close family and friends nurturing. Both are 
focused on empathy, reassurance and comfort. One discussant expressed, "well women just attend ANC clinics for jabs and tests. However, the real support is at home where kogos (grandmothers) massage gently, comfort, and encourage'. There was a similar supposition on relatives or friends' companion; relatives, friends' and 'Kogo' provide enough moral and psychological support to make pregnancy, and delivery a routine process and not medical'. The informational, instrumental and emotional support enable smooth pregnancy, labour and delivery. One participant thought, 'mental stability is a very key element in any process, predominantly in life threatening conditions like pregnancy and delivery. Usually, support from close people reduces tension'.

Nonetheless, modern maternal services are devoid of these attributes yet presence of known support boosts the odds of easy and painless delivery. A discussant summed labour is a painful process particularly when you are just with total strangers. Whom do you seek consolation from? Where does the comfort touch come from particularly in facilities where the ring tone is push push...?' The continuous support extends to delivery yet conventional health facilities limit companions to waiting rooms as expounded ' $m y$ sisters, why do health workers expel our companions from delivery rooms? Please tell me, why?' Tellingly, health workers appreciate the roles and influence of companions in labour and delivery whilst noting the harmless nature of some cultural values to maternity services. An informant upheld, 'Africans are endowed with rich and powerful practices which when integrated with health services may spur motivation and satisfaction. A good example is the local midwife-pregnant support model'. He continued, 'we need to appreciate people's way of life, scan and adopt the harmless but useful practices into healthcare. Who knows, this may be a solution to some health care barriers'.

Delivery position and assistant: Childbirth assistant and delivery position are key determinants of choices of birthing sites. In this study, women yearned for places with varied delivery options. The discussants from subsets of Endo, and Embobut/Embolot (Sengwer) advanced the need for a variety of birthing positions such as squatting. One discussant in Endo opined that 'for women, with squatting experience, like me, the method is easy due to gravity support yet health workers are fixated with delivery bed. A partaker in Embobut had like considerations 'we deliver on the floor at home comfortably while others squat. I suggest for introduction of various birthing position within facilities' (suggestive laughter). However, the viability of various delivery positions was debatable. Key informants opposed citing health safety and security reasons.

Choice of delivery assistant is a dynamic social construct among the Marakwet. Social cultural values such as initiation, age, gender and experience play a central role in choice of delivery assistant. An informant confirmed that 'typical Marakwet particularly from more endowed sub units such as Endo, Kapchesum, Sengwer and Kimala are still culturally indoctrinated with delivery assistant norms and customs'. These values have been debunked by westernization and delocalization of health work force.

Delivery by nurse aid rather than trained health workers was a key issue that emerged during discussions. This finding suggests that consumers are aware of roles and responsibility of health worker categories. Lack of attention during labour and childbirth by facility assistant emerged as a key issue. The study revealed that health workers housed within the hospital monitor labour remotely. A quote from a discussant acknowledged that 'health workers in the spirit of multitasking oversee labour from a distant. Those housed in the hospital compound show up just when the baby is due or even after. Attention, therefore, is one area health workers need to improve'.

Placenta management: Placenta interpretation and disposal after childbirth are important tenets among the Marakwet. The examination and interpretation of placenta is elaborate and systematic. More important, the placenta is perceived to inform a woman's number of children, sexuality and sequence of sexuality. Women prefer to deliver in secluded ambience convenient for observation, interpretation and disposal of the placenta. A discussant capped, 'Marakwet value the disposal and interpretation of the placenta. It is an organ identical with woman fertility and family

DOI: http://dx.doi.org/10.4314/ejhs.v30i2.2 
homogeneity'. Nonetheless, the art of group interpretation, propaganda and envy are the hallmark of open places like home deliveries. A discussant stated, 'group interpretations have devalued home deliveries with gossips particularly, perceived poor outcome of placenta interpretation'. Another discussant alluded, 'traditionally, midwifes were entrusted with secrets of placenta interpretations but nowadays, the village is awash with perceived fertility stories'.

In contrast, hospital escapes are considered safe and heavenly for placenta interpretations. Hospitals settings have the allure of privacy and confidentiality necessary for placenta interpretation yet not optimized. A discussant summed, 'birthing is convenient in health facilities but there is no room for placenta examination and interpretation. Why can't health workers allow a few minutes for those interested in this placenta business?' Another discussant supported, 'could you please tell health workers to allow relatives/companions to examine and witness the disposal of the placenta. When this is done, women will go home in peace, knowing that the endowed organ is well managed'.

This perception also resonated with another respondent who indicated that 'our facility has set designated disposal places for placenta. Additionally, companions monitor the disposal in respect to the traditions. However, there is no room for interpretation'. A health facility key informant supported the assertion, 'the phenomenon of necessary-services- unfriendly-system is a hindrance to uptake of delivery services. The day system will be tweaked without compromising safety and quality to accommodate clients' needs, vital statistics will change'. Opportunities to observe and interpret the placenta in private setting such as facilities may counter the home blather syndrome, scaling up the choice of outlets for delivery.

Additionally, Marakwet women perceive that delivery has a routine process devoid of medication hence home deliveries. In contrasts, anxiety and prospect of placenta retention motivate young women to deliver in health facility. Nevertheless, the aura of disposing placenta in a pit latrine is unacceptable and a taboo. Designing of cultured friendly placenta disposal sites rather than toilets is a prospect.
Celebration of newborns: In Marakwet, a cultured celebration is the seal of successful delivery. However, this is limited in facilities. A partaker validated, "just as urbanites mark baby showers and birthdays, we also in the village celebrate our functions in style. A newborn is a big achievement for Marakwet women; the culture elaborates spontaneous celebration codes. The fete is also a communication to the man and the community that there is a new born'. A cultural expert complemented, 'birthing and communication of birthing outcome are serenaded functions among the Marakwet. However, westernization including hospitals services has skirted these customary values'.

Understood in this way, a cultivated model of celebration intervention is overdue. Underlying the proposal is an increased effort to promote choice and voice for service uptake. A key informant presupposed, 'we are reorganizing our institutions and personnel in line with new dispensation and cultural undertones. Underlying these changes is an increased effort to promote service delivery, acceptability, accessibility and availability. However, the voice of service users and providers are important if we are to realize universal healthcare'. Another health worker in a different facility said, 'the health system is discriminatory and demotivating. Presumably, patients are primed as robots without rights, norms and values. The sooner we change this notion, the better for services uptake'. This finding, then suggests the importance of inclusion of social approaches such as newborn celebrations in service care.

Mother-child welfare services: Mother-child welfare services such as massage, supply of merchandise (basins, slippers, baby clothes and sanitary) and food porridge are important. These services are already in some health centers, and the effect is significant. A quote from a discussant appreciated the importance of welfare services, 'Other than laboratory services, provision of uji (porridge) and tea drive women to Kamogo, a facility one kilometer away from this one (Kakimiti)'.

Privacy and confidentiality: The study found privacy and confidentiality to be critical maternity services factors. One participant noted that 'secrecy and disclosure are significant dimensions to human

DOI: http://dx.doi.org/10.4314/ejhs.v30i2.2 
moralities and are protected under the Kenya constitution. These rights have not been respected over time and might work against the objectives of universal health care'. The key issues related to privacy and confidentiality are multiple vaginal examinations, unrestricted delivery rooms and male or uninitiated assistant. The discussants anticipated a mechanism to bridge the gap between the demands of the hospital operations and the absences of privacy. However, this topic calls for wider discussions on patient welfare systems in the context of limited infrastructure. In the words of one key informant, 'there are myths and perceptions which inform community and individual health seeking decisions in this society. It is worthwhile to exploit plausible health education and promotion approaches that may spur change in women ways of thinking and behaviour'. Additionally, it is deducible that misuse and over use of gloves by health worker influence choice of birthing sites. For this reason, promotion of health and hygiene use of PPEs among health workers is a critical subject in the competence care.

Multiple vaginal examinations in labour by different providers was of concern. One participant said, 'it is difficult to be intruded by several hands. The staff rotation and schedule system is set up in way that staff interchange roles within a certain period and this means vaginal examination by outgoing as well as the incoming staffs. This actual abridges on continuous care, privacy and exposures.' A key informant, however, contrasted this finding and decried the shortage of personnel as hindrance to application of continuous care by one nurse. She said, 'the sub county is characterized by shortage of personnel. We optimize the few available in the best way possible. In fact, if it were not for many volunteers, we would be in crises.

\section{DISCUSSION}

Support and companionship during pregnancy, delivery and post-delivery: The study has shown that support and companionship is a systematic personalized and community process aimed at reassuring and comforting the woman during the physiologically and nutritionally demanding pregnancy and lactating periods. This finding supports the results of Rono et al., that reports that Marakwet women may shun hospitals adrift of social and cultural values (18). Sharma et al., adds that, the current maternity approaches of women giving birth without the support of families disconnects and segregates mothers (19).

The absences of these support services have led to belief that childbirth in hospitals are detaching. The study infers that support services bestow native Marakwet woman power to exercise while passing along a modicum of labour and childbirth. This narrative is well documented (19, 20, 21). Furthermore, cultured birthing centre is known to provide greater involvement, satisfaction and attachment (19) as well as enhanced uptake of services (20). Gibson-Helm et al, infers that cultured birthing centre offers continuous quality improvement initiative (21). For this reason, known companion makes an integral component of cultured maternity service.

Delivery position and assistant: Birthing site and position inform delivery health seeking behaviour and choices. This finding agrees with Hlatywayo, who reports that correct and preferred birthing position contribute to African indigenous knowledge and practice systems on pregnancy and childbirth (22). In the current study, perspective on birthing choice is speckled. A supine position was common, but there was a call for other delivery options. The benefits of delivering in alternative positions compared to supine positions for normal births such as shorter labour duration, fewer episiotomies and fewer second-degree tears are provided (23). This finding communicates that the comfortability and perceived safety of delivery positions fluctuate among women. Either way, it is worth undertaking research on the perceived possible benefits and risks of the use of different birth positions. Sharm in a mixedmethods investigation into the quality of care at the time of birth at public and private sector maternity facilities in Uttar Pradesh, India, make reference that freedom to choose birthing position is an interpersonal aspect of care which is important during labour and birthing process (24).

According to Oikawa at al., comfortable delivery position increases the ease of delivery and may relieve mothers' pains (25). Choice of birthing position has been positively associated with maternal satisfaction (25). This is further supported by Sharma, who writes that lack of birthing position choice, not informing women prior to a vaginal examination, not allowing birth companions, not explaining reasons for augmentation of labour, restricting food and water and informal payments as key elements of disrespect and abuse (24). Gupta et al., in a Cochrane review advances that women should be encouraged to give birth in whatever position they find comfortable (23). It is consequently evident that offering woman a

DOI: http://dx.doi.org/10.4314/ejhs.v30i2.2 
choice of birthing position as part of cultural care may spur satisfaction and uptake.

Delivery assistants and their roles are central subjects. The major roles include known support: companionship as well as leketio delivery, placenta management, and decision-guides. It is the study suggestion that when these important aspects of care are adopted and implemented, provider-client compatibility and experience will improve. Additionally, safety and security are vital maternal needs. A similar finding is documented by M Iravani et al., who opines that when health providers are in delivery rooms, mothers feel secure and labour may scale down (26). However, the proposition of having nurse aid such as in the scenario depicted earlier in this study may instill fear and low selfesteem.

It is hypothesized that delivery by unskilled personnel such as nurse aid may affect duration of labour and even spontaneous delivery. Iravani et al credence that nurse aid may introduce needless intervention during labour and delivery (26). This may explain earlier findings of several unexplained vaginal examinations in facilities. In this study, the findings show that women are aware of core roles and responsibilities of categories of health workers. Participant expects nurses to deliver and not to delegate. In the context of achieving goals of reducing the number of unskilled care whilst increasing the nurses or midwifes, making skilled delivery assistant a key aspect of culture competence care is important. In addition, within the context of promoting health outcomes and good client-provider partnership, reminding health workers of the core roles and expectation of the women is timely.

Placenta management: Placenta interpretation and disposal are crucial maternal principles among the Marakwet. Women prefer to deliver in friendly ambience convenient for privacy and observational practices such as interpretation and disposal of the placenta. Additionally, the study revealed that home deliveries are the hallmark of group interpretation culminating in propaganda or envy on one's fertility. The finding on propaganda and jealousy are congruent with KabakianKhasholian and Portela's finding. The scholars write that women are worried of gossips and are even skeptical of being exposed to companion in hospital who may later blather them about not being able to keep up with social expectations of labour, such as not losing control and not shouting (27).

On the other hand, the prospect of placenta retention is motivates young generation into facility deliveries. Hospital setting has the allure of privacy and confidentiality necessary for placenta management yet not optimized. Since communities prefer known person to be close to them during delivery, opportunities to observe and interpret placenta in perceived safe places like hospitals may counter the midwife gossip disorder. Health management and health workers need to be abreast of such cultural practice. Marakwet, burying the placenta and the aura of disposing placenta in a pit latrine is immoral. Rono et al supports this narrative and reaffirms that the taboos associated with the disposal of placenta influence the choice of birthing site (18). Similar rituals exist in Northern Sumatra, Hungary, Japanese, Austria, Italy, Native Hawaiian, Navajo and Maori (18). In Samoa, it is believed that stepping over a placenta may influence how a woman conceives (28).

It is evident that the Marakwet treat the placenta like a live body, and its management is key in their health seeking behaviour. According to Rono et al., the proper management and disposal of the placenta will not only contribute to the health and general wellbeing of the mother and baby but also informs satisfaction (18). Consequently, it is important for health workers to understand these placenta dynamics and discuss its disposal with the woman or their representatives.

Celebration after childbirth: The study revealed that cultured celebrations are the seal of successful delivery but the opportunity to revel is limited in facilities. This finding concurs with Dodzo and Mhloyi's results. Dodzo and Mhloyi report that when pregnancy and childbirth are planned and intended, they are usually associated with joy and celebration (29). The deficiencies of hospital celebrations create social and personal dilemmas among women or their families. Agola, concurs that the birth of a child is a big celebration (30).

Sharma et al., adds that inclusion of social approaches in designing health services to mitigate social constructs, such celebration will anchor a balance for care (19). Iravani et al, in a qualitative study strengthens the narrative by reporting that knowing a woman's needs, values, preferences and expectations during normal labor and delivery assists healthcare professionals especially in providing high-quality care (26). Hence, the need to empower healthcare professionals for increased celebration opportunities.

Mother-child welfare services: The study disclosed that material needs are major factors in uptake of maternity services. Fatigue, exhaustion, burnout during labour stages was documented. As a coping strategy, women desired to drink or eat light food in between labour or delivery. The World Health Organization anticipates that providers do not restrict eating and drinking during labor to low risk women (26). The report continues that nutrition and individual hygiene items are key categories of physiological needs of women in labour and delivery (26). Grounded on these evidence, it is the study's proposition that introduction of the mother-child welfare services in maternity places may spur uptake of maternity

DOI: http://dx.doi.org/10.4314/ejhs.v30i2.2 
service. The main items are soft food, pads, basin, soaps and baby clothes.

Privacy and confidentiality: Privacy and confidentiality during labour and pregnancy inform choices and preference of birthing sites. Tukur et al., concurs with this finding (31). The scholars writes that the common reasons for aversion to facility delivery is lack of privacy and exposure to non-relatives and men. To the contrary, a safe, private and calm environment positively influenced the women's sense of control (26). Secondly, security need was dominant in this study. Women were anxious of their health in the absences of health workers and feared of childbirth before their arrival. According to Iravani et al. assurance of professional presence influences the women's sense of control (26). The psychological support of healthcare professionals is therefore a major ingredient in cultured care.

The study deduced several needs not limited to social cultural, informational, psychological and physiological ones. These needs are pregnancy and labor support and companionship, elective delivery methods, placenta interpretation, placenta disposal, celebrations, privacy and mother-child welfare. The WHO guidelines call for incorporation of the patient's wishes, beliefs as part of care plan through transforming provider preconceptions on expressed needs (32). Principled on the WHO guidelines, a model in which hospital accord women companions of their choice and the companions are given humble environment to support in desired services is endorsed. The analysis infers that women maternity needs and requirements are unique, multiple and diverse.

The study revealed that continuous support, elective childbirth options, opportunity to interpret and dispose placenta, celebration and privacy are important social cultural maternal health needs. These maternal healthcare needs are absent in the current healthcare landscapes. Absences of these support services have led to concerns that hospital delivery services are detaching and segregating. Integration of harmless but important needs into existing maternal policies may elicit broad based impact towards maternal and child health services. Additionally, enriching the knowledge and skills of service providers with perceived cultural needs and practices may help demystify and tackle retrogressive practices.

Strengths and limitations: The strengths of this research include the stratification of sub clans/catchment and key informants to document unique and diverse traditions in and between groups. Rapid analysis, co-creation and immersion sessions widened and enriched the understandings and interpretations of emerging themes. The limitations include verbatim presentation rather than contextual translation for perfect reporting. The aim was howeverto present the finding in its raw form.

\section{ACKNOWLEDGEMENTS}

The authors appreciates all the participants in the study, County Government of Elgeyo/Marakwet, Health Workers in Marakwet East and Marakwet open sources team who helped in data immersion and co-creation sessions.

\section{REFERENCES}

1. Zimu-Biyela AN. The management and preservation of indigenous Knowledge in Dlangubo Village In Kwazulu-Natal, South Africa [Internet]. Vol. 3, IOSR Journal of Economics and Finance. 2016. Available from: https://www.bertelsmannstiftung.de/fileadmin/files/BSt/Publikationen/Grau ePublikationen/MT_Globalization_Report_2018.p df\%0Ahttp://eprints.Ise.ac.uk/43447/1/India_global isation $\% 2 \mathrm{C}$ society and inequalities $\% 281$ sero $\% 29$.pdf\%0Ahttps://www.quo ra.com/What-is-the

2. Ishepe M.N, Kimuu, P W. Factors Associated with access and utilization of health care services by vulnerable and marginalized population in Kenya. Afr J Health Sci. 2015;28(5):432-41.

3. Servan-Mori E, Torres-Pereda P, Orozco E, SosaRubí SG. An explanatory analysis of economic and health inequality changes among Mexican indigenous people, 2000-2010. Int J Equity Health. 2014;13:21.

4. AIHW. Australia's Health 2014. Australia's health series no. 14. Cat. no. AUS 178. J Biol Chem. 2014 Aug 10;251(14):314-5.

5. Horn P. Indigenous Peoples, Poverty, and Development. J Dev Stud. 2014 50(11):1588.

6. Newman L, Baum F, Javanparast S, O’Rourke K, Carlon L. Addressing social determinants of health inequities through settings: A rapid review. Health Promot Int. 2015;30:ii126-43.

7. Tariq A., Durrani S. (2018) One Size Does Not Fit All: The Importance of Contextually Sensitive mHealth Strategies for Frontline Female Health Workers. In: Baulch E., Watkins J., Tariq A. (eds) mHealth Innovation in Asia. Mobile Communication in Asia: Local Insights, Global Implications. Springer, Dordrecht.

8. Elmusharaf K, Byrne E, O’Donovan D. Strategies to increase demand for maternal health services in resource-limited settings: Challenges to be addressed. BMC Public Health. 2015;15(1):1-10. 
Available from: http://dx.doi.org/10.1186/s12889015-2222-3

9. Wilson-Stronks A, Lee KK, Cordero CL, Kopp AL, Galvez E. One Size Does Not Fit All: Meeting the Health Care Needs of Diverse Populations. 2008.

10. Coast E, Jones E, Portela A, Lattof SR. Maternity care services and culture: A systematic global mapping of interventions. PLoS One. 2014;9(9):1.

11. Iravani, M., Zarean, E., Janghorbani, M., \& Bahrami, M. (2015). Women's needs and expectations during normal labor and delivery. Journal of education and health promotion, 2015;4(6):31-37. doi:10.4103/2277-9531.151885

12. Anne R, Dean K. Cultural Competence. Nursing Women's Health. 2010;14(1):50-9.

13. Jones, E., Lattof, S.R. \& Coast, E. Interventions to provide culturally appropriate maternity care services: factors affecting implementation. $B M C$ Pregnancy Childbirth 2017;18(267):310.https://doi.org/10.1186/s12884-017-1449-7

14. Sabera Turkmani, Dawson A, Hons BA, Ao CSEH. Maternity care experiences and health needs of migrant women from female genital mutilation practicing countries in high- income contexts: A systematic review and meta- synthesis. Wiley. 2019;46(1):3-14.

15. Kipchumba P. Aspects of Indigenous Religion among the Marakwet of Kenya. First. Kipchumba Foundation. Nairobi: Kipchumba Foundation; 2017. $1-51$.

16. Nandjila RT. Utilisation of post natal care services in the Grootfontein health district, Otjozondjupa region. The University of Namibia; 2008.

17. Graneheim UH, Lundman B. Qualitative content analysis in nursing research: Concepts, procedures and measures to achieve trustworthiness. Nurse Educ Today. 2004;24(2):105-12.

18. Rono A, Maithya H, Sorre B. Culture and Birthing: Experiences from a Rural Community in Western Kenya. Sociol Anthropol. 2018;6(1):56-63.

19. Sharma S, Kolahdooz F, Launier K, Nader F, June Yi K, Baker P, et al. Canadian Indigenous Womens Perspectives of Maternal Health and Health Care Services: A Systematic Review. Divers Equal Heal Care. 2016;13(5):217-24.

20. Vance A, McGaw J, Winther J, Rayner M. Towards an Aboriginal Knowledge Place: Cultural Practices as a Pathway to Wellness in the Context of a Tertiary Hospital. Int J Indig Heal. 2016;11(1):244.

21. Gibson-Helm ME, Rumbold AR, Teede HJ,
Ranasinha S, Bailie RS, Boyle JA. Improving the provision of pregnancy care for Aboriginal and Torres Strait Islander women: A continuous quality improvement initiative. BMC Pregnancy Childbirth. 2016;16(1):1-11.

22. Hlatywayo AM. Indigenous knowledge, beliefs and practices on Pregnancy and childbirth among the Ndau People of Zimbabwe. 2017;

23. Gupta JK, Sood A, Hofmeyr GJ VJ. Cochrane Database of Systematic Reviews Position in the second stage of labour for women without epidural anaesthesia (Review) Position in the second stage of labour for women without epidural anaesthesia (Review). 2017;(5). Available from: www.cochranelibrary.com

24. Sharma G. An Investigation into Quality of Care at the Time of Birth at Public and Private Sector Maternity Facilities in Uttar Pradesh, India. University of London; 2017.

25. Oikawa M, Sonko A, Faye EO, Ndiaye P, Diadhiou M, Kondo M. Assessment of maternal satisfaction with facility-based childbirth care in the rural region of Tambacouda, Senegal. Afr J Reprod Health. 2014;18(4):95-104.

26. Iravani M, Zarean E, Janghorbani M, Bahrami M. Women's needs and expectations during normal labor and delivery. J Educ Health Promot. 2015;4:6.

27. Kabakian-Khasholian T, Portela A. Companion of choice at birth: Factors affecting implementation. BMC Pregnancy Childbirth. 2017;17(1):1-13.

28. Abbato S. Community Profiles for Health Care Providers. Div Chief Heal Off Queensl Heal Brisbane. 2011.

29. DodzoMK, MhloyiM. Homeisbest:Why womenin rural Zimbabwe deliverin thecommunity. PLoSONE, 2017;12(8):e0181771.

30. Agola A. Experiences of Childbirth by Women and their Care Providers in Narok and Isiolo Counties, Counties , Kenya. 2012;(May).

31. Turkson P. Perceived quality of healthcare delivery in a rural District of Ghana. Ghana Med $J$. 2011;43(2):65-70.

32. Langins M, Borgermans L. Strengthening a competent health workforce for the provision of coordinated/integrated health services. World Health Organization, Working document. 2015; Available from: http://www.euro.who.int/_data/assets/pdf_file/001 0/288253/HWF-Competencies-Paper-160915final.pdf 